\title{
Splenosis involving the gastric fundus, a rare cause of massive upper gastrointestinal bleeding: a case report and review of the literature
}

This article was published in the following Dove Press journal:

Clinical and Experimental Gastroenterology

22 September 2016

Number of times this article has been viewed

\author{
Jason Reinglas' \\ Kirstin Perdrizet ${ }^{\prime}$ \\ Stephen E Ryan ${ }^{2}$ \\ Rakesh V Patel' \\ 'Department of Medicine, \\ ${ }^{2}$ Department of Diagnostic Imaging, \\ University of Ottawa, Ottawa \\ Hospital, Ottawa, ON, Canada
}

\begin{abstract}
Splenosis, the autotransplantation of splenic tissue following splenic trauma, is uncommonly clinically significant. Splenosis is typically diagnosed incidentally on imaging or at laparotomy and has been mistakenly attributed to various malignancies and pathological conditions. On the rare occasion when splenosis plays a causative role in a pathological condition, a diagnostic challenge may ensue that can lead to a delay in both diagnosis and treatment. The following case report describes a patient presenting with a massive upper gastrointestinal bleed resulting from arterial enlargement within the gastric fundus secondary to perigastric splenosis. The cause of the bleeding was initially elusive and this case highlights the importance of a thorough clinical history when faced with a diagnostic challenge. Treatment options, including the successful use of transarterial embolization in this case, are also presented.
\end{abstract}

Keywords: therapeutic, endoscopy, UGIB, intervention

\section{Introduction}

Splenosis refers to the autotransplantation of splenic tissue following a splenectomy or splenic trauma. It is thought to be secondary to the seeding and subsequent growth of splenic cells within the peritoneal cavity and, less commonly, within extraperitoneal locations. ${ }^{1-3}$ Given that splenosis is usually asymptomatic, its true incidence is unknown. ${ }^{4}$ The diagnosis of splenosis is usually made incidentally on imaging or at laparotomy, masquerading as benign or malignant tumors or other pathological conditions, such as endometriosis. ${ }^{5}$ It is uncommonly of clinical significance and despite the extent of neovascularization which occurs as the splenic tissue grows, major bleeding complications are rare. ${ }^{6}$ The following report describes a rare case of massive gastrointestinal bleeding secondary to perigastric splenosis that was treated successfully with transarterial embolization.

\section{Case}

A 52-year-old male with no previous history of gastrointestinal bleeding presented to the emergency department with chest pain and solid food dysphagia. His medical history included atrial fibrillation, hypertension, obstructive sleep apnea, asthma, and splenectomy at age 14 following a traumatic splenic rupture after being kicked by a horse. Initial cardiac workup was negative and he was discharged home with an outpatient follow-up appointment with gastroenterology.

His medications included dabigatran, diltiazem, irbesartan, montelukast, budesonide/formeterol, fluticasone/salmeterol, and salbutamol.
Correspondence: Jason Reinglas Department of Medicine, Ottawa Hospital, University of Ottawa, 407A - 737 Parkdale Ave, Ottawa, ON KIY IJ8, Canada Tel +l 6137985555 ext I3050

$\mathrm{Fax}+|61376| 4036$

Email jreing@gmail.com 
Outpatient upper endoscopy identified a Schatzki's ring at the esophageal-gastric junction as well as several small clean-based ulcers at the prepyloric region on a duodenum hiatus hernia. Biopsies were obtained from the gastric mucosa to rule out Helicobacter pylori. He was placed on a protonpump inhibitor and sent home following the procedure.

Four days later he re-presented to the emergency department with multiple episodes of melena, light-headedness, progressive shortness of breath on exertion, and rapid atrial fibrillation (heart rate $\sim 130 \mathrm{bpm}$, normotensive). Bloodwork revealed: hemoglobin $112 \mathrm{~g} / \mathrm{L}$ (baseline $\sim 150 \mathrm{~g} / \mathrm{L}$ ), mean corpuscular volume $83.8 \mathrm{fL}$, platelets $312 \times 10^{9} / \mathrm{L}$, creatinine $79 \mu \mathrm{mol} / \mathrm{L}$, urea $10.8 \mathrm{mmol} / \mathrm{L}$, international normalized ratio 1.2 , partial thromboplastin time 28 , and normal liver function tests. He was given $1 \mathrm{~L}$ of crystalloid, placed on a pantoprazole infusion, and his dabigatran was held.

Urgent upper endoscopy revealed stigmata of recent hemorrhage from recent biopsy sites, the previously observed clean-based ulcers, and a submucosal lesion in the third part of the duodenum, which was not bleeding. The biopsy sites were cauterized with a gold-probe and he was admitted for observation.

On post-admit day 2 , the patient had a syncopal episode associated with melena and a hemoglobin decline of $30 \mathrm{~g} / \mathrm{L}$. Repeat endoscopy revealed only a large adherent clot in the fundus, which could not be aspirated. The patient's melena persisted and hemoglobin continued to fall prompting another upper endoscopy that demonstrated a small pouch in the gastric fundus without any stigmata of recent hemorrhage, but concerning for either a diverticulum or fistula. A subsequent upper gastrointestinal series confirmed a mild focal out-pouching of the gastric fundus without any evidence of a fistula or leak. A computed tomography (CT) scan was performed and revealed replacement of the spleen by multiple soft tissue nodules consistent with splenosis, but could not identify a clear source of bleeding due to retained oral contrast within the stomach from the prior upper gastrointestinal series. On post-admit day 8 , the patient had a repeat CT scan which revealed a previously unidentified $1.3 \mathrm{~cm}$ perigastric lesion with moderate vascularity within the gastric fundus. The possibility of a gastric varix was raised. An endoscopic ultrasound was performed, which did not reveal any large varices, but did confirm a number of smaller perforating vessels within the fundal lesion, as well as several perigastric lesions, which were later identified as perigastric splenosis. Endoscopic ultrasound-assisted fine-needle aspiration of one of the perigastric lesions revealed a mixed population of lymphocytes, plasma cells, neutrophils, and eosinophils favoring a reactive lymph node, thus, nondiagnostic.
The patient continued to have melena stool and a subsequent CT angiogram was acquired revealing an extensive network of enlarged arteries within the wall of the gastric fundus that were supplying a grouping of splenosis along the posterior aspect of the gastric fundus (Figure 1). The dominant arterial supply was localized to a branch of the left inferior phrenic artery, which underwent successful transarterial coil embolization that was confirmed on a follow-up CT scan (Figures 1 and 2). The patient clinically improved, his hemoglobin stabilized, and he was ultimately discharged home.

Follow-up imaging 2 months later revealed further interval decrease in the size of the intramural gastric arterial collaterals perfusing the perigastric splenules. As of the most recent follow-up appointment 8 months following the patients' initial presentation, there was no further bleeding. Verbal consent was provided by the patient to have his data used in this study.

\section{Discussion}

Splenosis is an acquired condition that can arise following iatrogenic or traumatic splenic rupture. Residual viable splenic tissue can autotransplant throughout the peritoneal cavity and elsewhere, deriving its blood supply from adjacent tissues and organs..$^{5}$ The splenic implants are commonly found within the greater omentum due to its vascularity, which provides an ideal environment for regeneration and neovascularization. Additional potential sites of implantation include (in order of frequency): the serosal surface of the small bowel, parietal peritoneum, mesentery, diaphragm, intrahepatic, and intrathoracic. ${ }^{6-8}$ Although splenosis has been implicated in intestinal obstruction, gastrointestinal bleeding, and relapse of hematological diseases, patients are usually asymptomatic and the diagnosis is typically made incidentally on imaging or at laparotomy. ${ }^{3}$ As the ectopic splenic tissue may provide a degree of normal splenic function, asymptomatic splenosis is managed conservatively and resection is unnecessary. ${ }^{3,5,9}$

Diagnosing splenosis can be challenging given the extent and varied potential sites for autotransplantation as well as its relatively nonspecific appearance on conventional imaging modalities (ultrasound, CT, magnetic resonance imaging). As such, splenosis has been mistakenly reported as renal, adrenal, or abdominal tumors, metastases, lymphoma, endometriosis, and ectopic testicles. ${ }^{6}$ The diagnosis of splenosis can be confirmed by scintigraphy with technetium Tc $99 \mathrm{~m}$-labeled red blood cells. ${ }^{10,11}$ Biopsies taken from the splenic tissue of splenosis generally display characteristics consistent with splenic tissue, such as red and white pulp and marginal zones. ${ }^{5}$

Gastrointestinal bleeding secondary to splenosis is rare and usually occult. ${ }^{5,6}$ To our knowledge, three cases of massive upper gastrointestinal bleeding secondary to splenosis have 

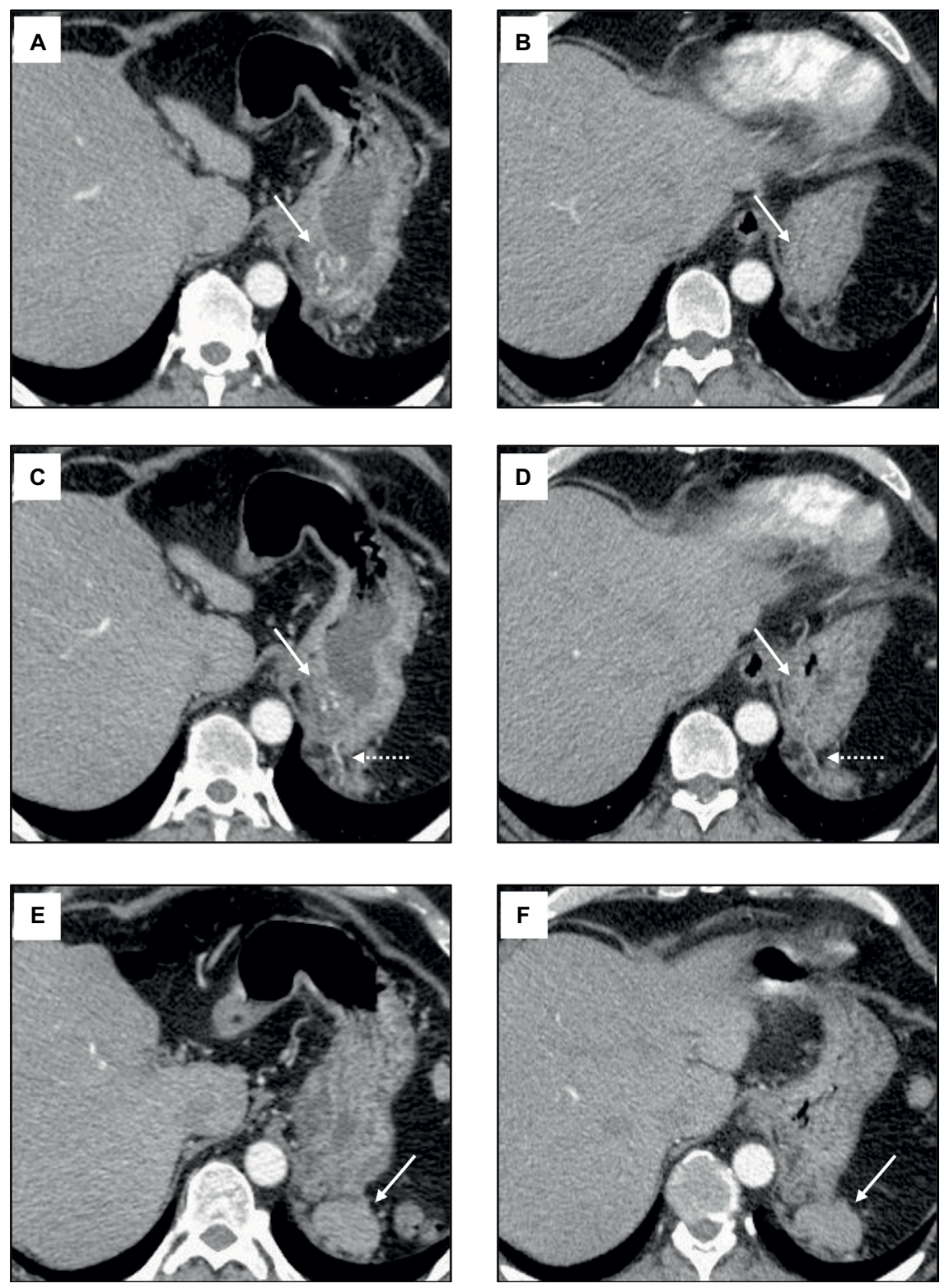

Figure I CT images of perigastric splenosis pre- and postembolization of the perfusing network.

Notes: (A) Selected contrast enhanced axial CT images acquired before (A, C, and E) and after (B, D, and F) embolization of an enlarged branch of the left inferior phrenic artery artery (as depicted by the solid arrows in A, B, C, and $\mathbf{D}$ ) perfusing a grouping of perigastric splenosis. (B) and (D) reveal near complete resolution of the tortuous component of the gastric branch traversing the wall of the gastric fundus. The dashed arrow in (C) and (D) reveals a corresponding marked reduction in size of the extramural component of the gastric branch leading to perigastric splenosis. The solid arrows in axial images $\mathbf{E}$ and $\mathbf{F}$ reveal the dominant nodule within the grouping of perigastric splenosis.

Abbreviation: $\mathrm{CT}$, computed tomography.

been reported in the literature. All cases required surgical resection for definitive management (Table 1). ${ }^{3,6,11}$ This is the first case of massive upper gastrointestinal bleeding secondary to splenosis involving the gastric fundus successfully managed through endovascular embolization.

\section{Bias}

Cognitive errors are common pitfalls in medicine and surgery. In practice, the anchoring heuristic implies relying on initial impressions to answer a clinical question. ${ }^{12}$ In our case report, the patient initially presented with a massive gastrointestinal bleed shortly following upper endoscopy and gastric biopsy. Despite the rarity of massive bleeding following routine endoscopic gastric biopsy, this became the initial working diagnosis. ${ }^{13}$ Following an additional episode of bleeding, a repeat upper endoscopy suggested the bleeding to be secondary to a gastric diverticulum, a more common cause than gastric splenosis. The disposition to consider a diagnosis as being more likely after being previously exposed to such a diagnosis defines the availability heuristic. ${ }^{12}$ As a consequence, arriving at the patient's true diagnosis was delayed. Finally, a CT scan demonstrated a perigastric vascular lesion, considered at one 

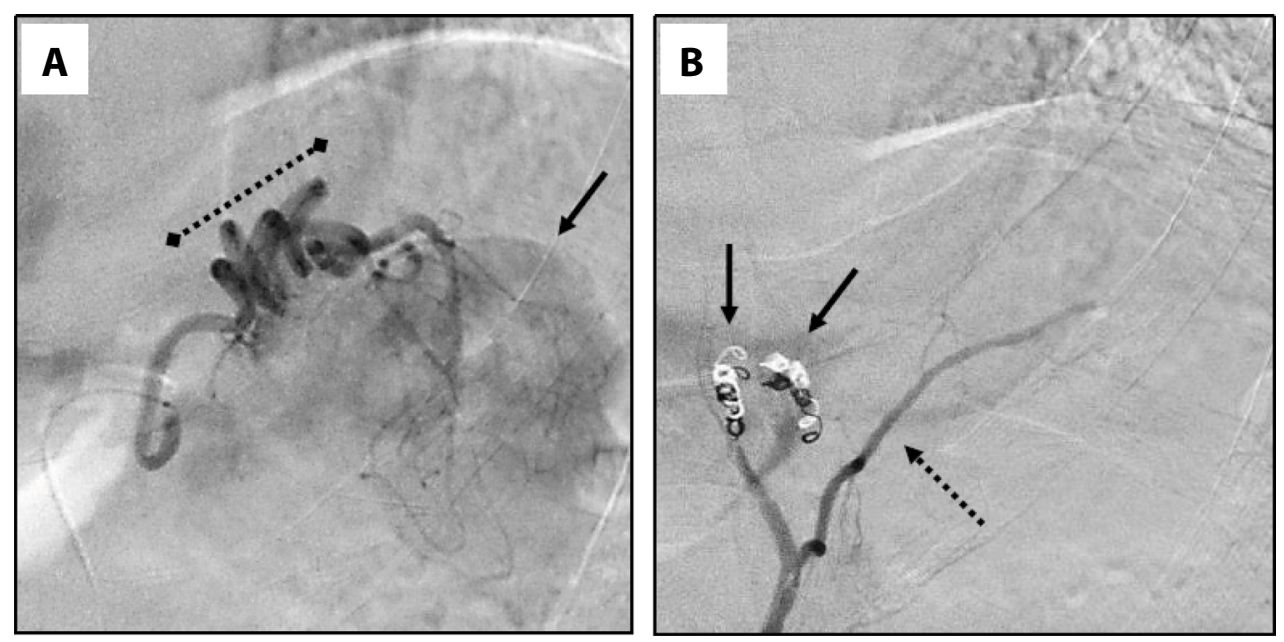

Figure 2 Selective angiogram and embolization of a gastric branch of the left phrenic artery perfusing the largest splenic nodule.

Notes: (A) Selective angiogram of a markedly enlarged gastric branch of the left phrenic artery perfusing the largest splenic nodule of a grouping of perigastric splenosis (arrow). The dashed line approximates the component of the artery traversing the wall of the gastric fundus. (B) Selective angiogram following successful embolization of the gastric branch with multiple coils (arrows). The dashed arrow identifies ascending branch of left inferior phrenic artery.

Table I Review of cases involving massive upper gastrointestinal bleeding secondary to splenosis*

\begin{tabular}{|c|c|c|c|c|c|}
\hline Author & Age (sex) & Splenosis location & Diagnostic confirmation & Intervention & Outcome \\
\hline Margari et $\mathrm{al}^{6}$ & $47(\mathrm{M})$ & Gastric & Histology & Surgical resection & $\begin{array}{l}\text { Survived intervention, } \\
\text { no follow-up reported }\end{array}$ \\
\hline Alang'I & $54(F)$ & Gastric & Histology & Surgical resection & $\begin{array}{l}\text { Survived intervention, } \\
\text { no follow-up reported }\end{array}$ \\
\hline Basile et $\mathrm{al}^{3}$ & $24(\mathrm{M})$ & Small bowel & $\begin{array}{l}\text { Technecium Tc } 99 \mathrm{~m} \text {-labeled red blood } \\
\text { cell scintigraphy, histology }\end{array}$ & Surgical resection & $\begin{array}{l}\text { Survived intervention, } \\
\text { no follow-up reported }\end{array}$ \\
\hline $\begin{array}{l}\text { Reinglas et al } \\
\text { (current study) }\end{array}$ & $52(M)$ & Gastric & $\begin{array}{l}\text { Triphasic computed tomography and } \\
\text { EUS }\end{array}$ & Transarterial embolization & $\begin{array}{l}\text { Survived intervention, } \\
\text { no recurrent bleeding } \\
\text { at follow-up }\end{array}$ \\
\hline
\end{tabular}

Notes: *Melena or hematochezia associated with hemodynamic instability (tachycardia, hypotension, presyncope, or syncope).

Abbreviations: EUS, endoscopic ultrasound; F, female; M, male.

point to be a potential gastric varix with therapeutic endoscopic injection of cyanoacrylate considered, further exemplifying the availability heuristic. Fortunately, the patient's underlying history was reconsidered and an endoscopic ultrasound performed ruling out gastric varices. Subsequent consultation with an interventional radiologist and acquisition of a triphasic CT scan ultimately uncovered the correct diagnosis and led to successful embolization of an enlarged branch of the left inferior phrenic artery perfusing a grouping or perigastric splenosis.

Interobserver variability may have played a role in delaying the diagnosis of the fundal lesion as well. A study conducted by Lau et al found the level of agreement between experts assessing the severity of bleeding peptic ulcers using video endoscopy was poor in more than a third of occasions. ${ }^{14}$ In our case report, each endoscopy was performed by a different gastroenterologist. Within large tertiary care facilities, it is unlikely an emergent procedure will be performed by the same interventionist on the same patient. As a result, interobserver variability is a potential source of bias.

\section{Conclusion}

Although the pathology was nondiagnostic and scintigraphy with technetium Tc $99 \mathrm{~m}$-labeled red blood cells was not performed, given the patient's course and findings on imaging, a diagnosis of splenosis was made and treated successfully. Thus, we suggest considering splenosis in the main differential diagnoses in patients presenting with upper gastrointestinal bleeding and a history of prior splenic trauma.

\section{Disclosure}

The authors report no conflicts of interest in this work.

\section{References}

1. Ludtke FE, Mack SC, Schuff-Werner P, Voth E. Splenic function after splenectomy for trauma. Role of autotransplantation and splenosis. Acta Chir Scand. 1989;155(10):533-539.

2. Gunes I, Yilmazlar T, Sarikaya I, Akbunar T, Irgil C. Scintigraphic detection of splenosis: superiority of tomographic selective spleen scintigraphy. Clin Radiol. 1994;49(2):115-117.

3. Basile RM, Morales JM, Zupanec R. Splenosis, a cause of massive gastrointestinal hemorrhage. Arch Surg. 1989;124(9):1087-1089. 
4. Normand JP, Rioux M, Dumont M, Bouchard G. Ultrasonographic features of abdominal ectopic splenic tissue. Can Assoc Radiol J. 1993; 44(3):179-184.

5. Sikov WM, Schiffman FJ, Weaver M, Dyckman J, Shulman R, Torgan P. Splenosis presenting as occult gastrointestinal bleeding. Am J Hematol. 2000;65(1):56-61.

6. Margari A,Amoruso M, D'Abbicco D, Notarnicola A, Epifania B. Massive gastrointestinal bleeding due to a splenotic nodule of the gastric wall. Chir Ital. 2008;60(6):863-865.

7. Brancatelli G, Vilgrain V, Zappa M, Lagalla R. Case 80: Splenosis. Radiology. 2005;234(3):728-732.

8. Wedemeyer J, Gratz KF, Soudah B, et al. Splenosis - important differential diagnosis in splenectomized patients presenting with abdominal masses of unknown origin. Z Gastroenterol. 2005;43(11): $1225-1229$.
9. Balfanz JR, Nesbit ME Jr, Jarvis C, Krivit W. Overwhelming sepsis following splenectomy for trauma. J Pediatr. 1976;88(3):458-460.

10. Bresciani C, Ferreira N, Perez RO, Jacob CE, Zilberstein B, Cecconello I. Splenosis mimicking gastric GIST: case report and literature review. Arq Bras Cir Dig. 2011;24(2):183-185.

11. Alang N. Splenosis: an unusual cause of massive gastrointestinal bleeding. R I Med J. 2013;96(11):48-49.

12. Croskerry P. The importance of cognitive errors in diagnosis and strategies to minimize them. Acad Med. 2003;78(8):775-780.

13. Domellöf L, Enander LK, Nilsson F. Bleeding as a complication to endoscopic biopsies from the gastric remnant after ulcer surgery. Scand J Gastroenterol. 1983;18(7):951-954.

14. Lau JY, Sung JJ, Chan AC, et al. Stigmata of hemorrhage in bleeding peptic ulcers: an interobserver agreement study among international experts. Gastrointest Endosc. 1997;46(1):33-36.

\section{Clinical and Experimental Gastroenterology}

\section{Publish your work in this journal}

Clinical and Experimental Gastroenterology is an international, peerreviewed, open access, online journal publishing original research, reports, editorials, reviews and commentaries on all aspects of gastroenterology in the clinic and laboratory. This journal is included on PubMed. The manuscript management system is completely online 